\title{
Synthesis and Evaluation of Changes Induced by Solvent and Substituent in Electronic Absorption Spectra of New Azo Disperse Dyes Containig Barbiturate Ring
}

\author{
Hooshang Hamidian, ${ }^{1}$ Najmeh Zahedian, ${ }^{2}$ Dadkhoda Ghazanfari, ${ }^{2}$ and Samieh Fozooni ${ }^{3}$ \\ ${ }^{1}$ Department of Chemistry, Payame Noor University (PNU), Tehran 19395-4697, Iran \\ ${ }^{2}$ Department of Chemistry, Azad University, Kerman, Iran \\ ${ }^{3}$ Zarand High Education Center, Mining Engineering Department, Shahid Bahonar University, Kerman, Iran
}

Correspondence should be addressed to Hooshang Hamidian; hooshanghamidian@yahoo.com

Received 29 June 2012; Revised 14 September 2012; Accepted 17 September 2012

Academic Editor: Damien Boyer

Copyright (C) 2013 Hooshang Hamidian et al. This is an open access article distributed under the Creative Commons Attribution License, which permits unrestricted use, distribution, and reproduction in any medium, provided the original work is properly cited.

Six azo disperse dyes were prepared by diazotizing 4-amino hippuric acid and coupled with barbituric acid and 2-thiobarbituric acid. Then, the products were reacted with aromatic aldehyde, sodium acetate, and acetic anhydride, and oxazolone derivatives were formed. Characterization of the dyes was carried out by using UV-Vis, FT-IR, ${ }^{1} \mathrm{H}$ NMR and ${ }^{13} \mathrm{C}$ NMR, and mass spectroscopic techniques. The solvatochromic behavior of azo disperse dyes was evaluated in various solvents. The effects of substituents of aromatic aldehyde, barbiturate, and thiobarbiturate ring on the color of dyes were investigated.

\section{Introduction}

It is well known that azo compounds are the most widely class of industrial synthesized organic dyes due to their versatile application in various fields, such as dyeing textilefiber, biological-pharmacological activities, and advanced application in organic synthesis [1-3]. Many heterocyclic compounds are used extensively in disperse dye chemistry for textile or nontextile applications. These dyes are now marketed to produce a full range of dispersed dyestuffs without the use of colorants based on heteroaromatic diazo components. Most of the heterocyclic dyes are derived from the diazo components consisting of five-membered rings containing one or more nitrogen heteroatoms, with the rings being fused into another aromatic ring [4].

The azo dyes containing heterocyclic rings result in brighter and often deeper shades than their benzene analogs. On the other hand, they are very important in applications such as disperse dyes for polyester fibers, reprography, functional dye and nonlinear optical systems, photodynamic therapy, and lasers [5-10].

Barbituric acid (pyrimidine 2,4,6 $(1 \mathrm{H}, 3 \mathrm{H}, 5 \mathrm{H})$-trione) is widely used in the manufacturing of plastics, pigments, dyes, polymers, and the Vitamin $B_{2}$ (riboflavin) synthesis [11-14]. Barbiturates are a class of drugs that are utilized as anesthetics and sleeping agents and are used for the treatment of anxiety, epilepsy, and other psychiatric disorders and possess effects on the motor and sensory functions [15]. 2-Thiobarbituric acid is also used in the 2-thioxo-2,3-dihydro-4,6 $(1 \mathrm{H}, 5 \mathrm{H})$ pyrimidinedione pharmacological and analytical fields [16, 17]. Therefore, several studies have been published on the synthesis and spectral properties of several azo barbituric acids so far [18-22]. We report the synthesis of a series of new azo dyes based on barbituric acid (Scheme 1).

The visible absorption spectra in various solvents of these dyes and effects of substituents of aromatic aldehyde, barbiturate, and thiobarbiturate ring on the color of dyes were also discussed.

\section{Experimental}

2.1. Materials and Apparatus. The chemicals used for the synthesis of the compounds were obtained from Merk Chemical Company and used without further purification.

The solvents used were of spectroscopic grade. IR spectra were determined using a Bruker tensor 27 Fourier 


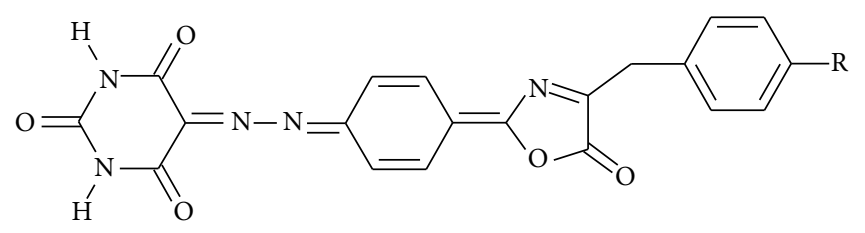

(4a): $\mathrm{R}=\mathrm{H},(\mathbf{4 b}): \mathrm{R}=\mathrm{Cl},(\mathbf{4 c}): \mathrm{R}=\mathrm{F}$

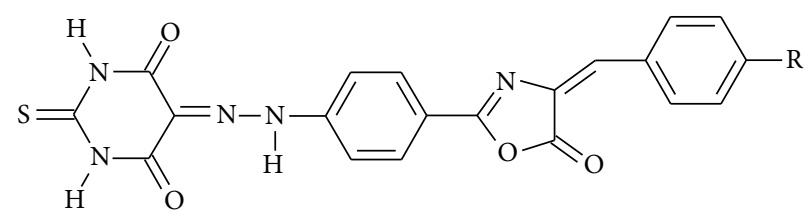

(4d): $\mathrm{R}=\mathrm{H},(\mathbf{4 e}): \mathrm{R}=\mathrm{Cl},(\mathbf{4 f}): \mathrm{R}=\mathrm{F}$

Scheme 1: Chemical structures of new azo dyes (4a-4f).

Transform-infrared (FT-IR) spectrophotometer on a $\mathrm{KBr}$ disc. Nuclear magnetic resonance $\left({ }^{1} \mathrm{H}\right.$ NMR) spectra were recorded on a Bruker-Spectrospin 400 Shimadzu QP-1100EX in dimethylsulphoxide (DMSO); chemical shifts were $(\delta)$ given in ppm. The microanalyses for $\mathrm{C}, \mathrm{H}$, and $\mathrm{N}$ were performed on perkin-elmer elemental analyzer. Ultravioletvisible (UV-vis) absorption spectra were recorded on an Perkin Elmer spectrophotometer at the wavelength of maximum absorption $\left(\lambda_{\max }\right)$ in a range of solvents, that is, dimethylsulphoxide (DMSO), dimethylformamide (DMF), and ethanol, at same concentrations $\left(1 \times 10^{-6} \mathrm{M}\right)$.

\subsection{Synthesis and Characterization}

2.2.1. Preparation of $A z$ o Dyes. $\mathrm{NaNO}_{2}(70 \mathrm{mg}, 1 \mathrm{mmol})$ was added to concentrated $\mathrm{HCl}(3.0 \mathrm{~mL})$ with external cooling. The suspension was heated to $60^{\circ} \mathrm{C}$ and again cooled to $0-5^{\circ} \mathrm{C}$.

To a cooled basic solution of 4-Amino hippuric acid $(1.94 \mathrm{~g}, 0.01 \mathrm{~mol})$ in sodium carbonate $(2.5 \%, 20 \mathrm{~mL})$ the prepared diazonium solution was added drop-wise and the mixture was stirred for $50 \mathrm{~min}$ at reaction $\mathrm{pH} 7$ (neutralized with sodium acetate). The precipitated product was filtered and purified by recrystallization from DMF/water $(8: 2)$.

(1) 2-[(4-2-[2,4,6-trioxotetrahydro)-5(2H)-pyrimidinyliden]hydrazino benzoyl) amino] acetic acid (3a). Yellow solid, yield $89 \%$, m.p. $289-291^{\circ} \mathrm{C}$; IR (KBr): $3423,3264,1750,1710$, $1654 \mathrm{~cm}^{-1}$; ${ }^{1} \mathrm{H}$ NMR (ppm): 12.33 (broad, $2 \mathrm{H}, \mathrm{NH}$ and $\mathrm{OH}$ ), $11.23(\mathrm{~s}, 2 \mathrm{H}, 2 \mathrm{NH}), 8.36$ (d, 2H, Ar-H), 7.63 (d, 2H, Ar$\mathrm{H}), 6.41(\mathrm{t}, 1 \mathrm{H}, \mathrm{NH}), 3.93\left(\mathrm{~d}, 2 \mathrm{H}, \mathrm{CH}_{2}\right) ;{ }^{13} \mathrm{C} \mathrm{NMR}(\mathrm{ppm})$ : $172.7,168.0,163.0,154.1,142.1,131.3,123.5,119.1,115.1$, 38.1; Anal. Calcd for $\mathrm{C}_{13} \mathrm{H}_{11} \mathrm{~N}_{5} \mathrm{O}_{6}$ : C, 46.85; $\mathrm{H}, 3.30 ; \mathrm{N}, 21.02$. Found: C, 47.01; H, 3.18; N, 20.95.

(2) 2-[(4-2-[4,6-dioxo-2-thioxotetrahydro)-5(2H)-pyrimidinyliden] hydrazino benzoyl) amino] acetic acid (3b). Orange solid, yield 81\%, m.p. 306-308 ${ }^{\circ} \mathrm{C}$; IR (KBr): 3424, 3252, 1703, $1653 \mathrm{~cm}^{-1}$; ${ }^{1} \mathrm{H}$ NMR (ppm): 12.38 (broad, $2 \mathrm{H}, \mathrm{NH}$ and $\mathrm{OH}$ ), 11.49 (s, 2H, 2NH), 8.42 (d, 2H, Ar-H), 7.67 (d, 2H, Ar-H), $6.41(\mathrm{t}, 1 \mathrm{H}, \mathrm{NH}), 3.92$ (d, $\left.2 \mathrm{H}, \mathrm{CH}_{2}\right) ;{ }^{13} \mathrm{C} \mathrm{NMR}$ (ppm): 178.2,
171.9, 167.8, 154.3, 143.1, 131.9, 122.9, 122.1, 115.0, 38.1; Anal. Calcd for $\mathrm{C}_{13} \mathrm{H}_{11} \mathrm{~N}_{5} \mathrm{O}_{5} \mathrm{~S}$ : C, 44.70; H, 3.15; N, 20.06. Found: C, 44.48; H, 2.94; N, 19.89 .

2.2.2. General Synthesis of Azo Dyes Containing Barbiturate Ring (4a-4f). A general preparative procedure is described below for the preparation of all dyes. 2-[(4- $\{2-[2,4,6-$ trioxotetrahydro)-5(2H)-pyrimidinyliden]hydrazino $\}$ benzoyl amino] acetic acid or 2-[(4-\{2-[4,6-dioxo-2-thioxotetrahydro)-5(2H)-pyrimidinyliden]hydrazino $\}$ benzoyl) amino] acetic acid (3.35 g or $3.50 \mathrm{~g}, 0.01$ mole) was refluxed in a mixture of sodium acetate $(1.50 \mathrm{~g})$, acetic anhydride $(15 \mathrm{~mL})$ and aromatic aldehydes $(0.03$ mole $)$ for $6 \mathrm{~h}$. The precipitated products were filtered off, washed with ethanol several times, dried, and recrystallized from dimethylformamide and water.

(1) 5-2-[4-(4-benzyl-5-oxo-2,5-dihydro-1,3-oxazol-2-yl)2,5-cyclohexadienyliden] hydrazono-2,4,6(1H,3H,5H)-pyrimidinetrione (4a). Yellow solid, yield 32\%, m.p. $326-327^{\circ} \mathrm{C}$; IR $\left(\mathrm{cm}^{-1}\right)$ : 3343 and $3265(\mathrm{~N}-\mathrm{H}), 1754(\mathrm{C}=\mathrm{O}$, oxazolone ring), 1710 and $1653\left(\mathrm{C}=\mathrm{O}\right.$, barbiturate ring); ${ }^{1} \mathrm{H}$ NMR (ppm): 11.56 (s, 1H, NH), 11.33 (s, 1H, NH), 7.41-8.85 (m, $9 \mathrm{H}, \mathrm{Ar}-\mathrm{H}$ and $\mathrm{CH}=\mathrm{C}), 4.15\left(\mathrm{~s}, 2 \mathrm{H}, \mathrm{CH}_{2}\right) ;{ }^{13} \mathrm{C} \mathrm{NMR}(\mathrm{ppm})$ : $171.8,169.2,166.1,162.4,160.2,150.2,144.1,135.7,131.4$, $131.1,130.1,129.4,126.9,119.2,116.5,21.0 ;$ MS: $m / z(\%)$ (70 ev EL) $403\left(\mathrm{M}^{+}\right), 257$ (0.75), 211 (3), 105 (22), 57 (88), 43 (100). Anal. Calcd for $\mathrm{C}_{20} \mathrm{H}_{13} \mathrm{~N}_{5} \mathrm{O}_{5}$ : C, 59.55; H, 3.22; N, 17.40. Found: C, 59.71; H, 3.46; N, 17.05.

(2) 5-(2-4-[4-(4-chlorobenzyl)-5-oxo-2,5-dihydro-1,3-oxazol-2-yl]-2,5-cyclohexadienylidenhydrazono)-2,4,6(1H,3H, $5 \mathrm{H}$ )-pyrimidinetrione (4b). Orange solid, yield 48\%, m.p. $325-328^{\circ} \mathrm{C}$; IR $\left(\mathrm{cm}^{-1}\right)$ : 3343 and $3264(\mathrm{~N}-\mathrm{H}), 1753(\mathrm{C}=\mathrm{O}$, oxazolone ring), 1710 and $1652\left(\mathrm{C}=\mathrm{O}\right.$, barbiturate ring); ${ }^{1} \mathrm{H}$ NMR (ppm): 11.57 (s, 1H, NH), 11.33 (s, 1H, NH), 7.63-8.85 $(\mathrm{m}, 8 \mathrm{H}, \mathrm{Ar}-\mathrm{H}$ and $\mathrm{CH}=\mathrm{C}), 3.92\left(\mathrm{~s}, 2 \mathrm{H}, \mathrm{CH}_{2}\right) ;{ }^{13} \mathrm{C} \mathrm{NMR}$ (ppm): 171.8, 169.1, 167.1, 162.4, 160.2, 150.2, 145.1, 131.5, $131.1,129.4,128.9,128.3,120.5,117.1,116.6,21.5 ; \mathrm{MS}: \mathrm{m} / z$ (\%) (70 ev EL) $437\left(\mathrm{M}^{+}\right), 257$ (29.6), 171 (26.97), 105 (90), 
TABLE 1: Experimental electronic absorption maxima for investigated dyes and solvent parameters [21-23].

\begin{tabular}{lcccccccccccc}
\hline \multirow{2}{*}{ Solvents } & \multirow{2}{*}{$\pi^{*}$} & \multirow{2}{*}{$\alpha$} & $\beta$ & $\varepsilon$ & \multicolumn{2}{c}{$n$} & \multicolumn{4}{c}{$\lambda_{\max }(\mathrm{nm})$} \\
& & & & $293 \mathrm{~K}$ & $293 \mathrm{~K}$ & & Dye (a) & Dye (b) & Dye (c) & Dye (d) & Dye (e) & Dye (f) \\
\hline DMSO & 1.00 & 0.00 & 0.76 & 47.24 & 1.4770 & 45.0 & 394.48 & 394.38 & 396.26 & 424.71 & 425.12 & 422.48 \\
DMF & 0.87 & 0.00 & 0.69 & 38.25 & 1.4305 & 43.8 & 393.04 & 392.85 & 393.39 & 423.04 & 424.64 & 421.57 \\
Ethanol & 0.54 & 0.83 & 0.77 & 25.33 & 1.3611 & 51.9 & 392.34 & 390.51 & 392.41 & 421.99 & 423.25 & 419.31 \\
\hline
\end{tabular}

85 (64), 43 (100). Anal. Calcd for $\mathrm{C}_{20} \mathrm{H}_{12} \mathrm{ClN}_{5} \mathrm{O}_{5}$ : C, 54.86; H, 2.74; N, 16.00. Found: C, 55.08; H, 2.94; N, 15.88 .

(3) 5-(2-4-[4-(4-fluorobenzyl)-5-oxo-2,5-dihydro-1,3-oxazol-2-yl]-2,5-cyclohexadienylidenhydrazono $)-2,4,6(1 \mathrm{H}, 3 \mathrm{H}$, $5 H)$-pyrimidinetrione (4c). Yellow solid, yield 61\%, m.p. 334-335 ${ }^{\circ}$; IR $\left(\mathrm{cm}^{-1}\right)$ : 3342 and $3265(\mathrm{~N}-\mathrm{H}), 1753(\mathrm{C}=\mathrm{O}$, oxazolone ring), 1710 and $1655\left(\mathrm{C}=\mathrm{O}\right.$, barbiturate ring); ${ }^{1} \mathrm{H}$ NMR (ppm): 11.55 (s, 1H, NH), 11.33 (s, 1H, NH), 7.24-8.85 (m, 8H, Ar-H and $\mathrm{CH}=\mathrm{C}), 3.91\left(\mathrm{~s}, 2 \mathrm{H}, \mathrm{CH}_{2}\right) ;{ }^{13} \mathrm{C} \mathrm{NMR}$ (ppm): 171.8, 169.1, 166.1, 162.5, 160.2, 150.2, 144.1, 132.2, $131.5,131.1,130.2,129.4,129.3,119.3,116.1,21.0 ;$ MS: $\mathrm{m} / z$ (\%) (70 ev EL) $421\left(\mathrm{M}^{+}\right), 393$ (1.66), 313 (14.58), 247 (3.33), 135 (80), 109 (35.42), 57 (91.66), 43 (100). Anal. Calcd for $\mathrm{C}_{20} \mathrm{H}_{112} \mathrm{FN}_{5} \mathrm{O}_{5}$ : C, 57.01; H, 2.85; N, 16.63. Found: C, 56.79; $\mathrm{H}, 3.03 ; \mathrm{N}, 16.47$.

(4) 5-(2-4-[5-oxo-4-[1-phenylmethylidene]-1,3-oxazol-2 (5H)-yllphenylhydrazono)-2-thioxodihydro-4,6(1H,5H)-pyrimidinedione (4d). Orange solid, yield 73\%, m.p. $322-325^{\circ} \mathrm{C}$; IR $\left(\mathrm{cm}^{-1}\right)$ : 3316 and $3262(\mathrm{~N}-\mathrm{H}), 1792(\mathrm{C}=\mathrm{O}$, oxazolone ring), 1689 ( $\mathrm{C}=\mathrm{O}$, thiobarbiturate ring); ${ }^{1} \mathrm{H}$ NMR (ppm): 14.2 (s, 1H, N-H), 12.36 (s, 1H, NH pyrimidine), 12.47 (s, $1 \mathrm{H}, \mathrm{NH}$ pyrimidine), 7.43-8.9 (m, 10H, Ar-H, $\mathrm{CH}=\mathrm{C}) ;{ }^{13} \mathrm{C}$ NMR (ppm): 178.1, 171.5, 169.3, 166.1, 163.5, 161.1, 159.0, 144.0, 135.3, 131.5, 130.9, 126.9, 120.2, 117.1, 116.4, 115.3; MS: $m / z(\%)\left(70\right.$ ev EL) $419\left(\mathrm{M}^{+}\right), 211$ (4.16), 105 (91.66), 77 (68.3), 43 (100). Anal. Calcd for $\mathrm{C}_{20} \mathrm{H}_{13} \mathrm{~N}_{5} \mathrm{O}_{4} \mathrm{~S}$ : C, 57.28; $\mathrm{H}$, 3.12; N, 16.71. Found: C, 57.41; H, 2.97; N, 16.58.

(5) 5-(2-4-[4-[1-(4-chlorophenyl)methylidene]-5-oxo-1,3oxazol-2(5H)-yl]phenylhydrazono)-2-thioxodihydro-4,6(1H, $5 \mathrm{H}$ )-pyrimidinedione (4e). Dark red solid, yield 40\%, m.p. 335-336 ${ }^{\circ}$; IR $\left(\mathrm{cm}^{-1}\right)$ : 3342 and $3246(\mathrm{~N}-\mathrm{H}), 1792(\mathrm{C}=\mathrm{O}$, oxazolone ring), 1688 (C=O, thiobarbiturate ring); ${ }^{1} \mathrm{H}$ NMR (ppm): 14.14 (s, 1H, N-H), 12.50 (s, 1H, NH pyrimidine), 12.47 (s, 1H, NH pyrimidine), 7.51-8.50 (m, 9H, Ar-H, $\mathrm{CH}=\mathrm{C}) ;{ }^{13} \mathrm{C}$ NMR (ppm): 178.0, 171.8, 169.1, 166.1, 162.4, $160.2,158.6,144.9,134.8,131.4,131.1,129.4,119.2,117.1$, 116.6, 114.1; MS: $m / z(\%)$ (70 ev EL) $435\left(\mathrm{M}^{+}\right), 297$ (4.68), 271 (3.57), 158 (62.5), 139 (91.5), 111 (32.18), 43 (100). Anal. Calcd for $\mathrm{C}_{20} \mathrm{H}_{12} \mathrm{ClN}_{5} \mathrm{O}_{4} \mathrm{~S}$ : C, 52.92; H, 2.65; N, 15.44 . Found: C, 53.03; H, 2.69; N, 15.28.

(6) 5-(2-4-[4-[1-(4-fluorophenyl)methylidene]-5-oxo-1,3oxazol-2(5H)-yl]phenylhydrazono)-2-thioxodihydro-4,6(1H, $5 H)$-pyrimidinedione (4f). Orange solid, yield 67\%, m.p. $320-322^{\circ} \mathrm{C}$; IR $\left(\mathrm{cm}^{-1}\right): 3323$ and $3260(\mathrm{~N}-\mathrm{H}), 1791(\mathrm{C}=\mathrm{O}$, oxazolone ring), 1688 ( $\mathrm{C}=\mathrm{O}$, thiobarbiturate ring); ${ }^{1} \mathrm{H}$ NMR (ppm): 14.2 (s, 1H, N-H), 12.63 (s, 1H, NH pyrimidine), 12.46 (s, 1H, NH pyrimidine), 7.23-8.85 (m, 9H, Ar-H and $\mathrm{CH}=\mathrm{C}) ;{ }^{13} \mathrm{C}$ NMR (ppm): 178.1, 171.7, 169.1, 166.1, 164.3, 160.2 , 158.7, 145.1, 131.5, 131.1, 129.4, 128.3, 120.4, 119.6, 117.1, 115.9; MS: $m / z$ (\%) (70 ev EL) $347\left(\mathrm{M}^{+}\right), 393$ (93.8),
378 (3.5), 336 (15.5), 296 (59.5), 280 (31.2), 135 (9.5), 43 (100). Anal. Calcd for $\mathrm{C}_{20} \mathrm{H}_{12} \mathrm{FN}_{5} \mathrm{O}_{4} \mathrm{~S}: \mathrm{C}, 54.92 ; \mathrm{H}, 2.75 ; \mathrm{N}$, 16.02. Found: C, 55.10; H, 2.64; N, 15.91 .

\section{Results and Discussion}

2-[(4-2-[2,4,6-trioxotetrahydro)-5(2H)-pyrimidinyliden]hydrazino benzoyl) amino] acetic acid (3a) and 2-[(4-2[4,6-dioxo-2-thioxotetrahydro)-5(2H)-pyrimidinyliden]hydrazino benzoyl) amino] acetic acid (3b) were prepared by diazotization of 4-amino hippuric acid (1) in nitrosyl hydrochloric acid followed by coupling with barbituric acid and 2-thiobarbituric acid. Then oxazolone azo dyes (4a-4f) were synthesized by classical Erlenmeyer reaction, involving condensation of azo dye products with corresponding aldehydes in presence of acetic anhydride and sodium acetate under refluxing condition (Scheme 2).

3.1. The UV-Visible Spectra and Solvatochromic Studies of New Dyes. In order to study of solvent effects on spectral features of the dyes, we recorded their absorption spectra in three solvents with different polarity at a concentration $10^{-6} \mathrm{M}$ in the range of 250-700 $\mathrm{nm}$ (Table 1), in which the solvents are arranged in the order of decreasing polarity. Also, refractive index $(n)$, dielectric constant $(\varepsilon)$, and the solvatochromic parameters $\left(\pi^{*}, \alpha\right.$, and $\left.\beta\right)$ were taken from the literature [23$25]$. As shown in Table 1, the electronic absorption spectra of all studied compounds in different solvents exhibit maximum absorption band $\left(\lambda_{\max }\right)$ in the range of 390.51-425.12 nm which can be attributed to $n \rightarrow \pi^{*}$ and/or $\pi-\pi^{*}$ electronic transitions of azo chromophores.

The dyes displayed a single main absorption peak without a shoulder in all solvents. The $\lambda_{\max }$ of all compounds were found to show a weak solvent dependency, denoting bathochromic effect (positive solvatochromism) in more polar solvents. The spectral shift is mainly due to solutesolvent interactions that give rise to a better stabilization of the $\pi^{*}$ orbital as compared to the $\pi$ orbital in polar solvents (Figure 1).

3.2. Substituent Effects. The absorption spectra of these azo dyes $\mathbf{4 a - 4 f}$ were recorded in various solvents at the concentration of $10^{-6}, \mathrm{M}$, and the results are given in Table 1 . We found that the electronic absorption of these azo dyes indicated a regular variation with the polarity of solvents, which did not change significantly. These dyes, apparently, did not exhibit a strong solvent dependence. The maximum absorption of these dyes shifted in the order: DMSO $>$ DMF $>$ Ethanol. The spectral shifts of dyes $\mathbf{4 a - 4 f}$ in various solvents 
<smiles>Nc1ccc(C(=O)NCC(=O)ON=[N+]([O-])C(Cl)Cl)cc1</smiles>

(1)

(2)<smiles>[X]C(=O)Nc1[nH]c(=O)c(=NNc2ccc(C(=O)NCC(=O)O)cc2)c(=O)[nH]c1[Y]</smiles><smiles>[R]c1ccc(C=O)cc1</smiles><smiles>[R]c1ccc(CC2=NC(=C3C=CC(=NN=C4C(=O)NC(=O)NC4=O)C=C3)OC2=O)cc1</smiles>

(4a): $\mathrm{R}=\mathrm{H},(\mathbf{4 b}): \mathrm{R}=\mathrm{Cl},(\mathbf{4 c}): \mathrm{R}=\mathrm{F}$<smiles>[R]c1ccc(C=O)cc1</smiles><smiles>[R]c1ccc(/C=C2/N=C(c3ccc(NN=C4C(=O)NC(=S)NC4=O)cc3)OC2=O)cc1</smiles>

(4d): $\mathrm{R}=\mathrm{H},(\mathbf{4 e}): \mathrm{R}=\mathrm{Cl},(\mathbf{4 f}): \mathrm{R}=\mathrm{F}$

SCHEME 2: Synthetic route for azo dyes containing barbiturate ring $\mathbf{4 a - 4 f}$.

are shown in Figure 1. The maximum absorption of dye 4a showed bathochromic shift in DMSO and DMF, with respect to the maximum absorption in ethanol (e.g., $\lambda_{\max }$ is $394.48 \mathrm{~nm}$ in DMSO, $393.04 \mathrm{~nm}$ in DMF, and $392.34 \mathrm{~nm}$ in ethanol). The same trends of absorption shifts in various solvents were observed for the entire series of dyes $\mathbf{4 a - 4 f}$, as shown in Table 1. The substituent effects of the heterocyclic azo dyes $\mathbf{4 a - 4 f}$ were evaluated. The spectral shifts of dyes $\mathbf{4 a -}$ 4f in solvents at a concentration of $10^{-6}$ are given in Table 2 . We found that the dyes $\mathbf{4 a - 4 f}$ did not exhibit a strong solvent dependence to substituent effects on the phenyl ring but exhibited a strong solvent dependence to thiobarbiturate or barbiturate ring. Therefore dyes $\mathbf{4 d} \mathbf{d} \mathbf{4} \mathbf{f}$ showed bathochromic shift in comparison with dyes $\mathbf{a}-\mathbf{c}$ in all studied solvents as shown in Table 2.

\section{Conclusions}

In summary, we have synthesized six disperse azo dyes containing barbiturate and thiobarbiturate ring (4a-4f) in this paper. The structures of prepared dyes were confirmed 


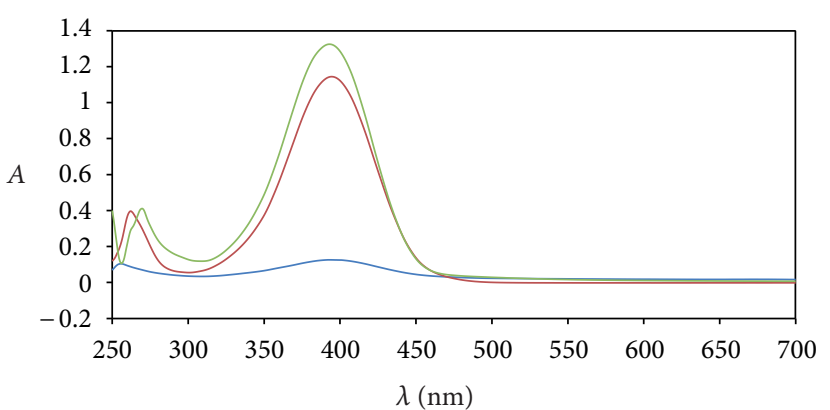

(a)

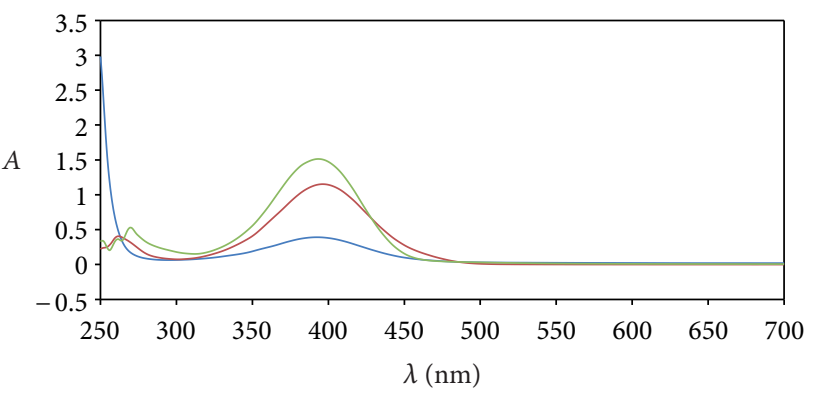

(c)

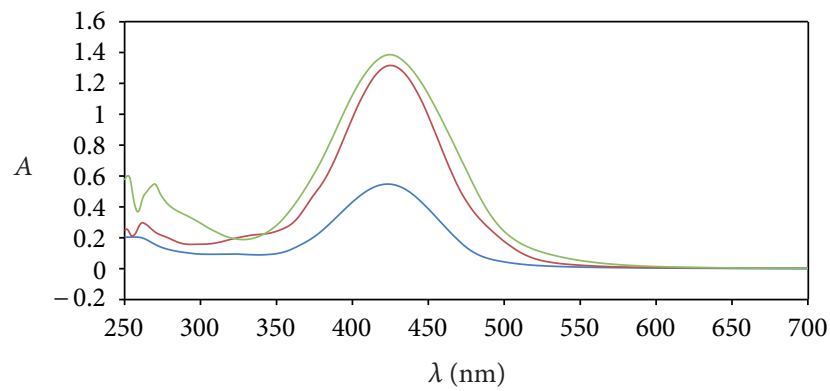

(e)

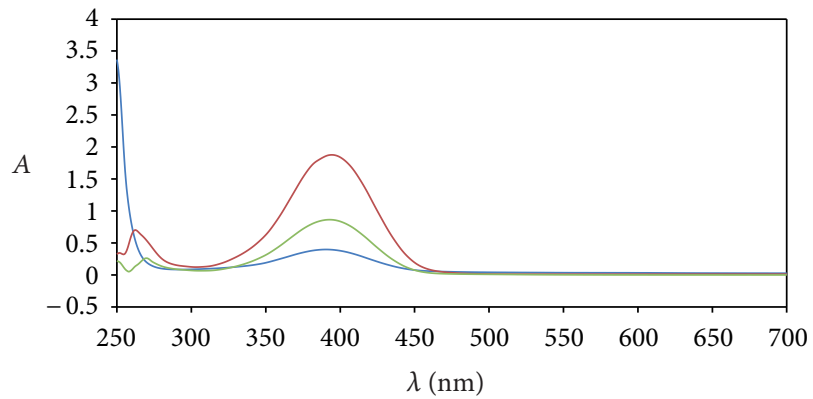

(b)

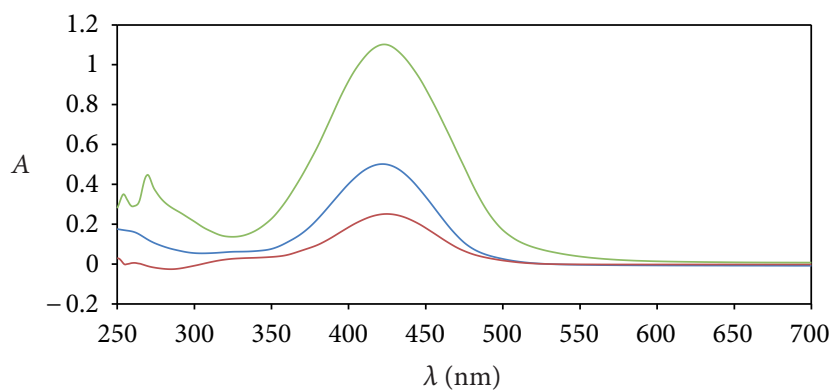

(d)

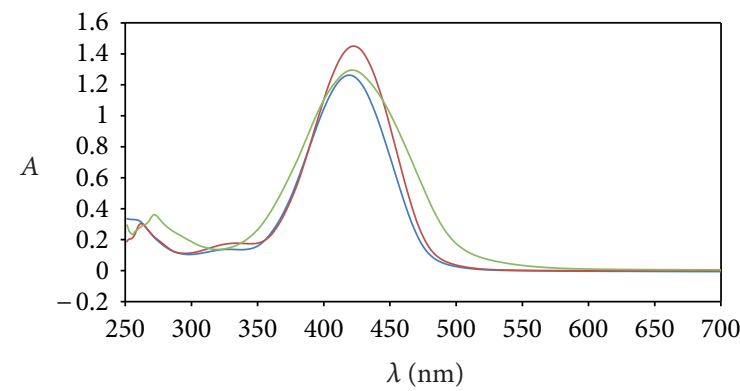

(f)

Figure 1: Electronic absorption spectra of azo dyes $(\mathbf{4 a}-\mathbf{4 f})$ at room temperature $\left(C=1.0 \times 10^{-6} \mathrm{~mol} \cdot \mathrm{L}^{-1}\right)$. (red) DMSO, (green) DMF, (blue) EtOH; (a) 4a, (b) 4b, (c) 4c, (d) 4d, (e) 4e, (f) 4f.

TABLe 2: Substituent effect of dyes $\mathbf{4 a - 4 f}$ in DMSO, DMF, and ethanol.

\begin{tabular}{lcccccccccrr}
\hline Dyes & $\mathrm{X}$ & $\mathrm{R}$ & \multicolumn{3}{c}{ DMSO } & \multicolumn{3}{c}{ DMF } & \multicolumn{3}{c}{ Ethanol } \\
& & & $\lambda_{\max }$ & $\Delta \lambda^{\mathrm{a}}$ & $\log \varepsilon$ & $\lambda_{\max }$ & $\Delta \lambda^{\mathrm{a}}$ & $\log \varepsilon$ & $\lambda_{\max }$ & $\Delta \lambda^{\mathrm{a}}$ & \multicolumn{1}{c}{$\log \varepsilon$} \\
\hline (a) & $\mathrm{O}$ & $\mathrm{H}$ & 394.48 & - & 6.07 & 393.04 & - & 6.17 & 392.34 & 5.07 \\
(b) & $\mathrm{O}$ & $\mathrm{Cl}$ & 394.38 & -0.10 & 6.25 & 392.85 & -0.19 & 5.93 & 390.51 & -1.83 & 5.68 \\
(c) & $\mathrm{O}$ & $\mathrm{F}$ & 396.26 & +1.78 & 6.05 & 393.39 & +0.35 & 6.17 & 392.41 & +0.07 & 5.68 \\
(d) & $\mathrm{S}$ & $\mathrm{H}$ & 424.71 & +30.23 & 5.40 & 423.04 & +30.00 & 6.04 & 421.99 & +29.65 & 5.69 \\
(e) & $\mathrm{S}$ & $\mathrm{Cl}$ & 425.12 & +30.64 & 6.11 & 424.64 & +31.60 & 6.17 & 423.25 & +30.91 & 5.70 \\
(f) & $\mathrm{S}$ & $\mathrm{F}$ & 422.48 & +28.00 & 6.11 & 421.57 & +28.53 & 6.09 & 419.31 & +26.97 & 6.09 \\
\hline
\end{tabular}

aelative to dye (a).

by ${ }^{1} \mathrm{H}$ NMR, ${ }^{13} \mathrm{C}$ NMR, mass spectroscopy, FT-IR, and UVvis spectra. The electronic absorption spectra of disperse dyes were recorded in solvents with different physicalchemical properties. A large bathochromic shift (positive solvatochromism) of these compounds was observed upon increasing the solvent polarity and the dyes $\mathbf{4 a - 4 f}$ did not exhibit a strong solvent dependence to substituent effects on the phenyl ring but exhibited a strong solvent dependence to thiobarbiturate or barbiturate ring.

\section{Acknowledgment}

The authors are very grateful to Azad University of Kerman for providing financial support of this study. 


\section{References}

[1] A. A. Fadda, H. A. Etman, F. A. Amer, M. Barghout, and K. S. Mohamed, "Azo disperse dyes for synthetic fibres. I: 2-methyland 2-phenylquinazolone derivatives," Journal of Chemical Technology and Biotechnology, vol. 61, no. 4, pp. 343-349, 1994.

[2] M. M. M. Raposo, A. M. R. C. Sousa, A. M. C. Fonseca, and G. Kirsch, "Thienylpyrrole azo dyes: synthesis, solvatochromic and electrochemical properties," Tetrahedron, vol. 61, no. 34, pp. 8249-8256, 2005.

[3] M. R. Yazdanbakhsh, A. Ghanadzadeh, and E. Moradi, "Synthesis of some new azo dyes derived from 4-hydroxy coumarin and spectrometric determination of their acidic dissociation constants," Journal of Molecular Liquids, vol. 136, no. 1-2, pp. 165-168, 2007.

[4] M. A. Weaver and L. Shuttleworth, "Heterocyclic diazo components," Dyes and Pigments, vol. 3, no. 2-3, pp. 81-121, 1982.

[5] L. C. Abbott, S. N. Batchelor, J. Oakes et al., "Experimental and computational studies of structure and bonding in parent and reduced forms of the azo dye orange II," Journal of Physical Chemistry A, vol. 109, no. 12, pp. 2894-2905, 2005.

[6] M. M. M. Raposo, M. C. R. Castro, A. M. C. Fonseca, P. Schellenberg, and M. Belsley, "Design, synthesis, and characterization of the electrochemical, nonlinear optical properties, and theoretical studies of novel thienylpyrrole azo dyes bearing benzothiazole acceptor groups," Tetrahedron, vol. 67, no. 29, pp. 5189-5198, 2011.

[7] P. C. Tsai and I. J. Wang, "A facile synthesis of some new pyrazolo[1,5-a]pyrimidine heterocyclic disazo dyes and an evaluation of their solvatochromic behaviour," Dyes and Pigments, vol. 74, no. 3, pp. 578-584, 2007.

[8] H. R. Maradiya and V. S. Patel, "Synthesis and dyeing performance of some novel heterocyclic azo disperse dyes," Journal of the Brazilian Chemical Society, vol. 12, no. 6, pp. 710-714, 2001.

[9] A. C. Razus, L. Birzan, N. M. Surugiu, A. C. Corbu, and F. Chiraleu, "Syntheses of azulen-1-yl-benzothiazol-2-yl diazenes," Dyes and Pigments, vol. 74, no. 1, pp. 26-33, 2007.

[10] J. A. Mielczarski, G. M. Atenas, and E. Mielczarski, "Role of iron surface oxidation layers in decomposition of azo-dye water pollutants in weak acidic solutions," Applied Catalysis B, vol. 56, no. 4, pp. 289-303, 2005.

[11] D. Thetford, A. P. Chorlton, and J. Hardman, "Synthesis and properties of some polycyclic barbiturate pigments," Dyes and Pigments, vol. 59, no. 2, pp. 185-191, 2003.

[12] A. V. Kulinich, N. A. Derevyanko, and A. A. Ishchenko, "Synthesis, structure, and solvatochromism of merocyanine dyes based on barbituric acid," Russian Journal of General Chemistry, vol. 76, no. 9, pp. 1441-1457, 2006.

[13] A. Slaczka and J. Lubczak, "Hydroxyalkylation of barbituric acid. IL synthesis of polyetherols with pyrimidine ring," Journal of Applied Polymer Science, vol. 106, no. 6, pp. 4067-4074, 2007.

[14] M. Tishler, K. Pfister, R. D. Babson, K. Ladenburg, and A. J. Fleming, "The reaction between o-aminoazo compounds and barbituric acid. A new synthesis of riboflavin," Journal of the American Chemical Society, vol. 69, no. 6, pp. 1487-1492, 1947.

[15] J. L. Fillaut, J. Andriès, J. Perruchon et al., "Alkynyl ruthenium colorimetric sensors: optimizing the selectivity toward fluoride anion," Inorganic Chemistry, vol. 46, no. 15, pp. 5922-5932, 2007.

[16] A. Dhasmana, J. P. Barthwal, B. R. Pandey, B. Ali, K. P. Bhargava, and S. S. Parmar, "Anticonvulsant activity and succinate dehydrogenase inhibitory property of new substituted thiobarbiturates," Journal of Heterocyclic Chemistry, vol. 18, no. 3, pp. 635-637, 1981.

[17] B. Morelli, "2-Thiobarbituric acid as a reagent for the determination of bismuth(III) by normal and derivative spectrophotometry," The Analyst, vol. 107, no. 1272, pp. 282-287, 1982.

[18] R. Gup, E. Giziroglu, and B. Kirkan, "Synthesis and spectroscopic properties of new azo-dyes and azo-metal complexes derived from barbituric acid and aminoquinoline," Dyes and Pigments, vol. 73, no. 1, pp. 40-46, 2007.

[19] M. S. Masoud, E. A. Khalil, A. M. Hindawy, A. E. Ali, and E. F. Mohamed, "Spectroscopic studies on some azo compounds and their cobalt, copper and nickel complexes," Spectrochimica Acta A, vol. 60, no. 12, pp. 2807-2817, 2004.

[20] A. H. Amrallah, N. A. Abdalla, and E. Y. El-Haty, "Mixed ligand complexes of benzimidazole and pyrimidine hydroxy azo dyes with some transition metals and glycine, DL-alanine or DLleucine," Talanta, vol. 46, no. 4, pp. 491-500, 1998.

[21] M. S. Masoud, S. A. Abou El-Enein, M. E. Ayad, and A. S. Goher, "Spectral and magnetic properties of phenylazo-6-aminouracil complexes," Spectrochimica Acta A, vol. 60, no. 1-2, pp. 77-87, 2004.

[22] M. S. Masoud, G. B. Mohamed, Y. H. Abdul-Razek, A. E. Ali, and F. N. Khairy, "Studies on some thiazolylazo compounds and their cobalt, nickel, and copper complexes," Spectroscopy Letters, vol. 35, no. 3, pp. 377-413, 2002.

[23] C. Reichardt, Solvents and Solvent Effects in Organic Chemistry, Wiley-VCH, Weinheim, Germany, 2003.

[24] M. J. Kamlet, J. L. M. Abboud, M. H. Abraham, and R. W. Taft, "Linear solvation energy relationships. 23. A comprehensive collection of the solvatochromic parameters, $\pi *, \alpha$, and $\beta$, and some methods for simplifying the generalized solvatochromic equation," Journal of Organic Chemistry, vol. 48, no. 17, pp. 2877-2887, 1983.

[25] D. R. Lide, Handbook of Chemistry and Physics, CRC Press, Boca Raton, Fla, USA, 76th edition, 1995. 

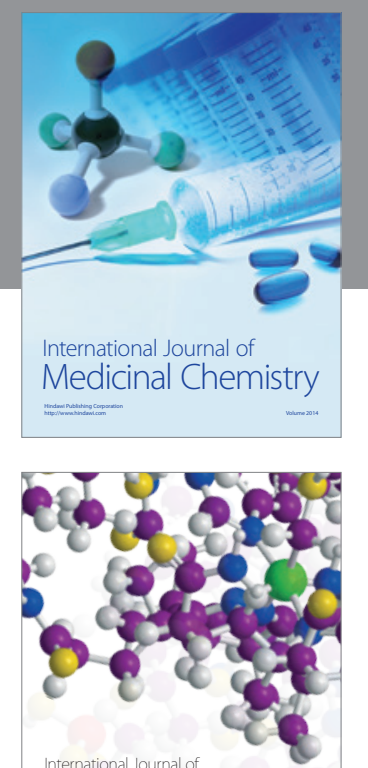

\section{Carbohydrate} Chemistry

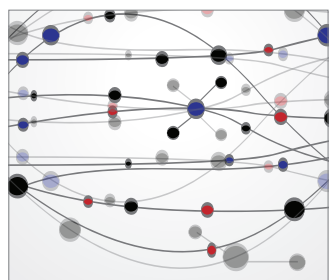

The Scientific World Journal
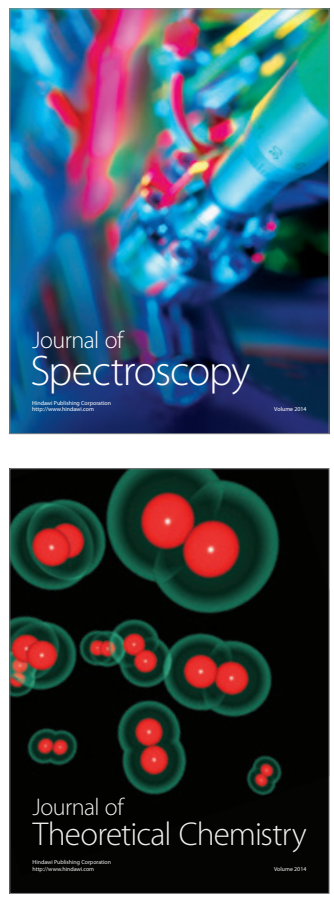
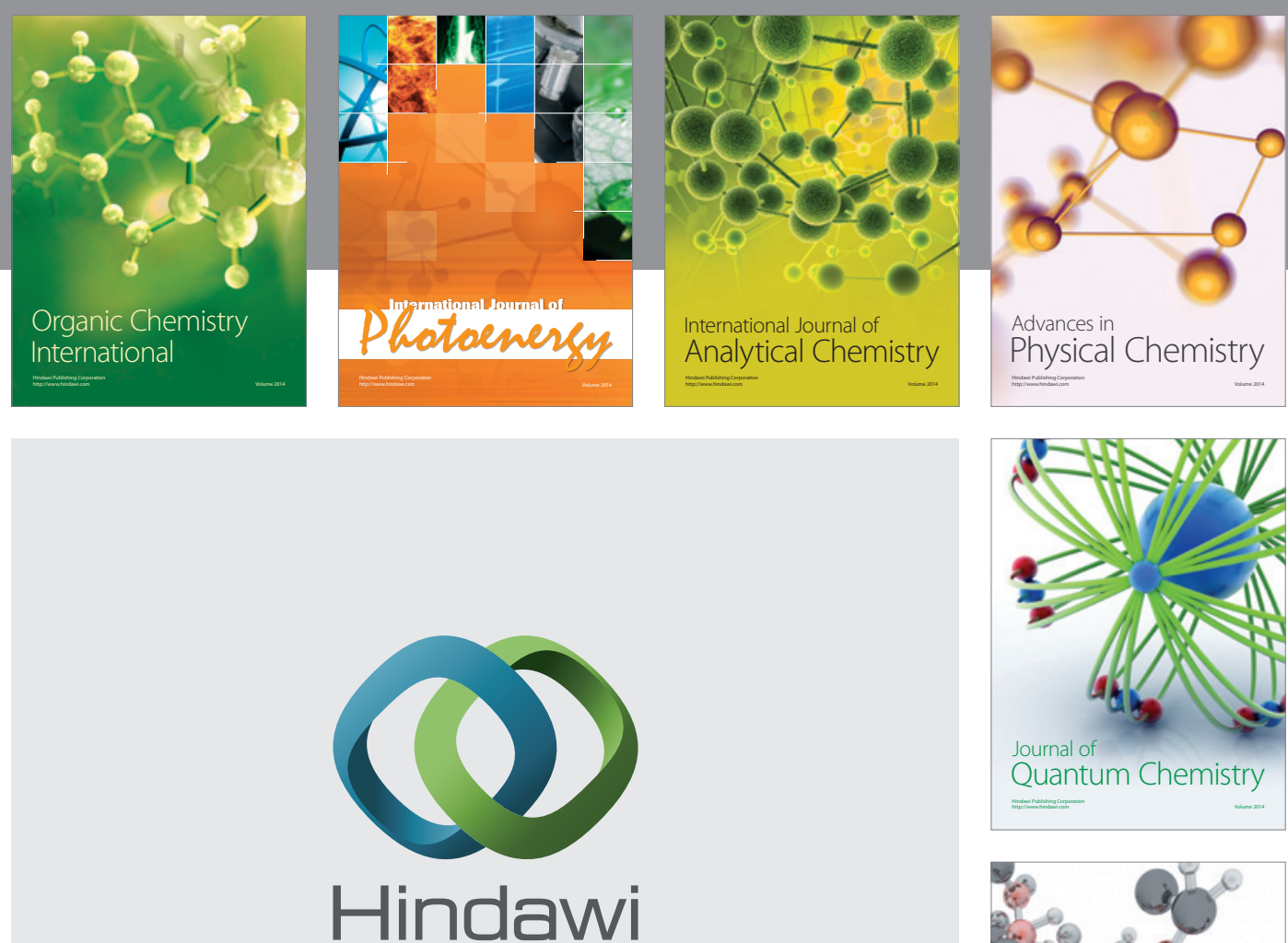

Submit your manuscripts at

http://www.hindawi.com

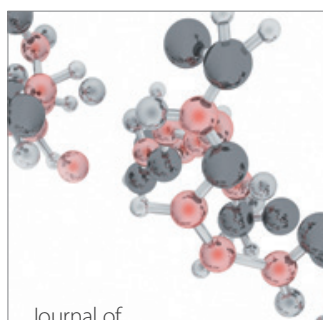

Analytical Methods

in Chemistry

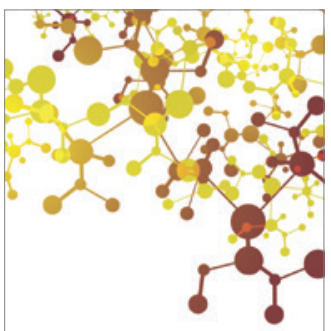

Journal of

Applied Chemistry

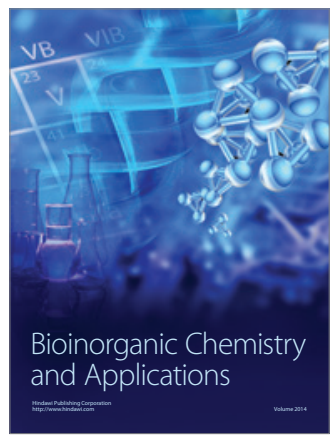

Inorganic Chemistry
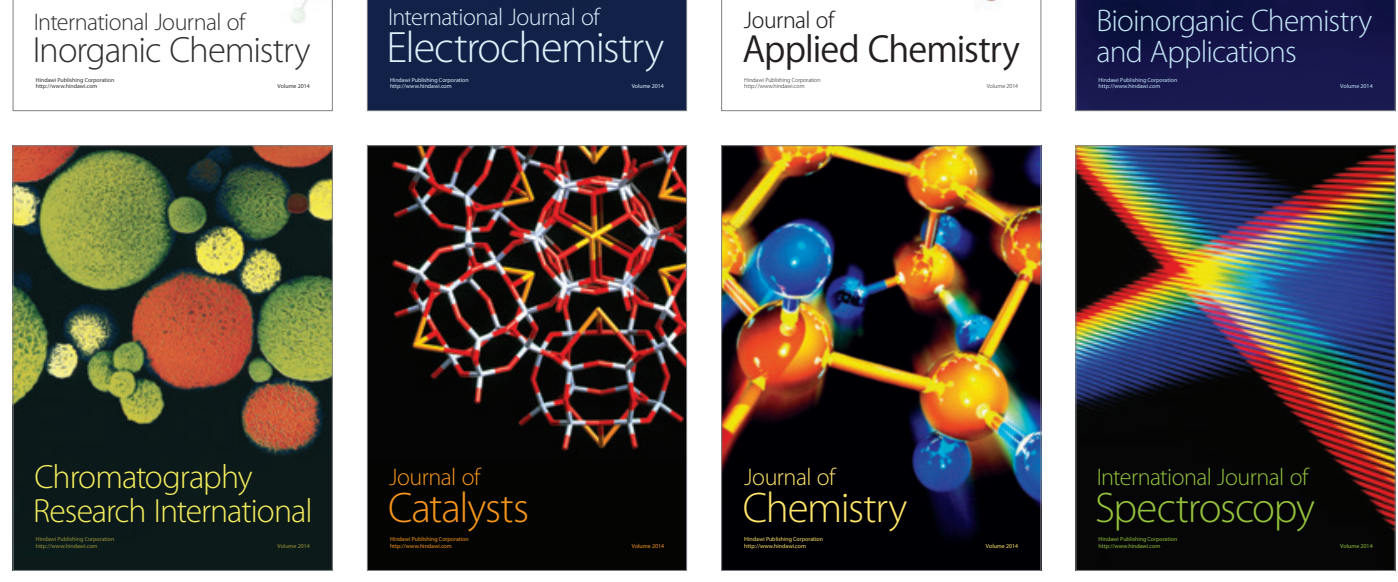